\title{
Stability of Whole Blood Lactate Specimens at Room Temperature Versus Slushed Ice Conditions
}

\author{
Gerald S Zavorsky, Samuel Gasparyan, Nicholas S Stollenwerk, and Rebecca A Brooks
}

\begin{abstract}
BACKGROUND: There are limited data on lactate stability in whole blood. The purpose of this study was to determine whole blood lactate stability at room temperature and in slushed ice conditions. METHODS: An equal number of arterial and venous samples were obtained from 202 subjects hospitalized for various pathophysiological conditions. Whole blood lactate concentration was measured over 5 different times spanning 80-90 $\mathrm{min}$ in a blood gas lab at a major hospital center. Samples were stored at room temperature $\left(22-24^{\circ} \mathrm{C}\right)$ or in slushed ice conditions $\left(0.1-0.2^{\circ} \mathrm{C}\right)$ before analysis. RESULTS: The mean increase in lactate concentration was $0.001 \mathrm{mmol} / \mathrm{L} / \mathrm{min}$ in samples on slushed ice over $90 \mathrm{~min}$. However, at room temperature conditions, the mean increase in lactate concentration was $0.008 \mathrm{mmol} / \mathrm{L} / \mathrm{min}$ regardless of whether the sample was arterial or venous. An increase in whole blood lactate concentration of $\geq 0.4 \mathrm{mmol} / \mathrm{L}$ occured after $45 \mathrm{~min}$ at room temperature, with $5 \%$ of all whole blood specimens demonstrating a meaningful change at $\leq 20 \mathrm{~min}$. The $\geq 0.4 \mathrm{mmol} / \mathrm{L}$ change in whole blood lactate is considered significant based on the College of American Pathologists instrument peer-group standards. CONCLUSIONS: Considering that a change in whole blood lactate concentration of $\geq 0.4 \mathrm{mmol} / \mathrm{L}$ is unacceptable instrument peer-group variation as defined by the College of American Pathologists, ice is no longer needed to stabilize whole blood lactate specimens when the draw time to analyze time is $<\mathbf{4 5}$ min. Samples remain stable even at 90 min when left on ice. Key words: lactic acid; kinetics; time-course; critically ill; meaningful change. [Respir Care 2021;66(3):494-500. (C) 2021 Daedalus Enterprises]
\end{abstract}

\section{Introduction}

The measurement of blood lactate concentration has been used to aid physicians in the management of various pathophysiological conditions in patients, such as infection, diabetic ketoacidosis, cardiogenic or hemorrhagic shock, cardiac arrest, burns and smoke inhalation, trauma, sepsis or septic shock, liver failure, or malignancy. ${ }^{1}$ Critical lactate levels $\geq 4.0 \mathrm{mmol} / \mathrm{L}$ are associated with in-hospital mortality and can be used in emergency departments as a

\footnotetext{
Dr Zavorsky is affiliated with the Pulmonary Services and Blood Gas Laboratories, University of California Davis Medical Center, Sacramento, California. Mr Gasparyan is affiliated with the Respiratory Therapy Program, San Joaquin Valley College, Rancho Cordova, California. Dr Stollenwerk is affiliated with the Department of Internal Medicine, Division of Pulmonary, Critical Care, and Sleep Medicine, University of California Davis Medical Center, Sacramento, California. Dr Brooks is affiliated with the Division of Gynecologic Oncology, University of California Davis Medical Center, Sacramento, California.
}

risk-stratification tool and to guide medical decisionmaking. ${ }^{2,3}$

Because monitoring blood lactate concentration is essential for patient management, it is understandable that major hospital centers receive thousands of whole blood lactate specimens per year to be processed. At our institution, there is a dedicated blood gas lab, staffed by respiratory therapists, which is separate from the main clinical lab. This dedicated blood gas lab mostly processes venous, arterial, and capillary blood specimens for blood gases, electrolytes, and metabolites. For example, in 2019 , this blood gas lab received 34,284 arterial or

\footnotetext{
Radiometer America provided a high-volume solution pack and a highvolume sensor cassette for this study. The authors have disclosed no conflicts of interest.

Correspondence: Gerald S Zavorsky PhD RPFT Pulmonary Services Laboratory, UC Davis Medical Center, 2315 Stockton Boulevard, Room 5703, Sacramento, CA 95817. E-mail: gszavorsky@ucdavis.edu.
}

DOI: $10.4187 /$ respcare.08023 
venous whole blood specimens from 11,146 patients that were processed for lactate only to facilitate patient management. The current protocol mandates that all whole blood lactate specimens be placed on ice before transport to the lab. Placing whole blood specimens on ice would seem logical because red blood cells are entirely dependent on glycolysis for the production of adenosine triphosphate (ATP). ${ }^{4}$ As such, having ice surround the specimen would slow down the use of glucose, decrease the production of lactate in these red blood cells, and minimize falsely increased results.

However, the use of ice may be unnecessary if the specimen is analyzed promptly. The use of ice can waste resources, including materials and time. For example, having $\geq 200 \mathrm{~mL}$ of ice surround each specimen resulted in about $8,550 \mathrm{~L}$ of ice $(7,700 \mathrm{~L}$ of water) utilized in 2019 at our institution. Furthermore, when electrolyte analysis is also needed, an extra syringe of room temperature blood is necessary per many protocols. This results in additional resources including patient blood, syringes, and staff time. Moreover, accessing the arterial or intravenous lines frequently to obtain multiple blood samples from a patient can increase infection risk.

Neither the time course over which lactate increases nor the necessity to keep lactate on ice has been well defined. As such, the purpose of this study is to define the rate of lactate accumulation in samples over time and to determine the length of time that a specimen of whole blood lactate can be kept at room temperature conditions before a clinically meaningful change (ie, increase) in lactate of $\geq 0.4 \mathrm{mmol} / \mathrm{L}$ occurs. A clinically meaningful change of $\geq 0.4 \mathrm{mmol} / \mathrm{L}$ was decided upon as it is the value used by the College of American Pathologists (CAP) in their surveys to determine peer group (same instrument) unacceptability across laboratories in the United States.

\section{Methods}

This was an observational, prospective cohort study. Whole blood venous and arterial patient specimens were obtained from the blood gas lab at University of California Davis Medical Center, in Sacramento, California, between October 2019 and February 2020. The blood gas lab is accredited by the State of California Department of Public Health (Lab ID CDF0002547; CLIA Number 05D0615654) and by the College of American Pathologists (CAP Number 2422006). The samples obtained were sent to the lab via a pneumatic tubing system. All samples were analyzed with the Radiometer ABL 90 Flex blood gas analyzer (Radiometer Medical, Brønshøj, Denmark). The samples were analyzed first for patient care, and then they were de-identified for this study. Only samples that were within the analytical measurement range of the instrument were used for this study (ie, blood lactate concentration of $0.70-16.0 \mathrm{mmol} / \mathrm{L}$ ).

\section{QUICK LOOK}

\section{Current knowledge}

The Clinical and Laboratory Standards Institute recommends a storage time of $\leq 15 \mathrm{~min}$ for whole blood lactate at room temperature. Otherwise, the specimens should be stored on ice to prevent falsely elevated values. These recommendations were based on studies of 3-5 patients.

\section{What this paper contributes to our knowledge}

In analysis of blood lactate specimens $(n=100)$, we demonstrate that whole blood lactate increases by $0.008 \mathrm{mmol} / \mathrm{L} / \mathrm{min}$ at room temperature conditions. As such, when the draw-to-analyze time is $<45 \mathrm{~min}$, storing a whole blood arterial or venous lactate specimen on ice is no longer necessary.

Most samples were obtained from 3-mL Portex line draw arterial blood sample syringes with 23.5 IU dry lithium heparin per mL (Ref 4042-2, Smiths Medical, Minneapolis, Minnesota). Vented 3-mL Portex ProVent arterial sampling kits with 23.5 IU dry lithium heparin per mL (Ref 4598P-2, Smiths Medical) were also used for several samples.

Samples were stored at room temperature $\left(22-24^{\circ} \mathrm{C}\right)$ or on slushed ice $\left(0.1-0.2^{\circ} \mathrm{C}\right)$ for $80-90 \mathrm{~min}$. Measurements were obtained at 5 different times: baseline (minute 0 ) and approximately 20, 40, 60, and $80 \mathrm{~min}$ after receiving the sample. Each blood sample at each time was mixed thoroughly for $5 \mathrm{~s}$ in both upright and inverted positions before inserting the sample into the analyzer. All bubbles were removed prior to analysis. If the sample had been stored on slushed ice, the syringe was placed vertically in a container containing slushed ice. The temperature of the slushed ice bath was measured via 2 thermometers (Fisherbrand Traceable Refrigerator/Freezer Plus Thermometer, Thermo Fisher Scientific, Pittsburgh, Pennsylvania), and the temperatures of the 2 thermometers were averaged. The reported accuracy of the thermometers was $\pm 0.5^{\circ} \mathrm{C}$.

The University of California Davis institutional review board reviewed the project (ID 1469859-1) and determined that this research was exempt because it did not involve human subjects and no patient identifying information was obtained.

\section{Statistical Analysis}

A repeated measures analysis of variance was used to identify mean changes in whole blood lactate concentration (venous vs arterial samples) over the 5 different times at 2 
Table 1. Changes in Whole Blood Lactate Concentration at Different Temperatures*

\begin{tabular}{|c|c|c|c|c|}
\hline Time at room temperature $\left(22-24^{\circ} \mathrm{C}\right), \mathrm{min}$ & $22 \pm 3$ & $42 \pm 4$ & $62 \pm 5$ & $82 \pm 4$ \\
\hline Range of time, min & $16-33$ & $26-60$ & $53-100$ & 70-109 \\
\hline Change in whole blood lactate concentration $\dagger$ & $0.2 \pm 0.1$ & $0.4 \pm 0.1$ & $0.6 \pm 0.2$ & $0.8 \pm 0.3$ \\
\hline $95 \%$ bootstrapped CI of the mean change & $0.2-0.3$ & $0.4-0.5$ & $0.6-0.6$ & $0.7-0.8$ \\
\hline Time in slushed ice $\left(0.1-0.2^{\circ} \mathrm{C}\right), \mathrm{min}$ & $24 \pm 6$ & $45 \pm 11$ & $67 \pm 12$ & $89 \pm 15$ \\
\hline Range of time, $\min$ & $17-72$ & $38-114$ & $57-145$ & $77-178$ \\
\hline Change in whole blood lactate concentration & $0.1 \pm 0.1$ & $0.1 \pm 0.1$ & $0.1 \pm 0.1$ & $0.2 \pm 0.1$ \\
\hline $95 \%$ bootstrapped $\mathrm{CI}$ of the mean change & $0.1-0.1$ & $0.1-0.1$ & $0.1-0.1$ & $0.1-0.2$ \\
\hline $\begin{array}{l}\text { Data are presented as mean } \pm \text { SD unless otherwise noted. } \\
\text { * Whole blood }=\text { arterial and venous combined. } \\
{ }^{\circ} \text { Change at room temperature compared to baseline }(n=100) \text {. } \\
{ }^{*} \text { Change in slushed ice compared to baseline }(n=102) .\end{array}$ & & & & \\
\hline
\end{tabular}

different conditions (ie, room temperature and slushed ice). A Bonferroni correction was used to adjust for multiple comparisons and to determine post hoc differences.

A forward multiple linear regression was conducted to determine which independent variables (ie, arterial vs venous sample type, time from baseline measurement) were predictors of the change in lactate concentration from baseline. Another forward multiple linear regression was conducted to determine which independent variables (arterial vs venous sample type, change in lactate concentration) were predictors of the post-measurement time for the desired change in lactate concentration.

Data screening was utilized to identify outliers in linear regression analyses. Any data point that exceeded a standard deviation of the residuals $\geq 3.0$ during any screening was eliminated. Cases that were above the critical values for the chi-square distribution for Mahalanbois distance were also removed. For example, with one predictor, cases were removed when a Mahalanbois distance was $>6.63$ $(P=.01)$. A plot between the standardized residuals $(y$ axis) and standardized predicted values ( $x$ axis) was used to visualize the spread, which would indicate normality and homoscedasticity. When examining for multicollinearity, the variance inflation factor was used to see whether there was a strong association between the independent and dependent variables. All independent variables in the model must have a variance inflation factor $<10$. To examine if the errors were autocorrelated, a Durbin-Watson test was performed. The range is $0-4$. A value of nearly 2 indicates non-autocorrelation, a value close to zero indicates a positive autocorrelation, and a value close to 4 indicates a negative autocorrelation. To cross-validate the model for prediction accuracy, $80 \%$ of the cases were used to fit the linear equation, and then the model was used on the remaining $20 \%$ of the cases. A correlation coefficient was obtained between each of the predicted values and actual values for $20 \%$ of the cases. When a full model accounted for $<25 \%$ of the total variance, it was not included.
Data were analyzed with SPSS 26.0 (IBM Armonk, New York). An a priori $P$ value of .01 was used to signify statistical significance.

\section{Results}

One hundred whole blood samples (49 venous, 51 arterial) were used to examine the stability of lactate concentration over time at room temperature conditions $\left(22-24^{\circ} \mathrm{C}\right)$. The mean $\pm \mathrm{SD}$ baseline values for the venous and arterial specimens were $2.4 \pm 2.1 \mathrm{mmol} / \mathrm{L}$ and $1.8 \pm 1.4 \mathrm{mmol} / \mathrm{L}$, respectively. When the arterial and venous samples were combined, the baseline values were $2.1 \pm 1.8 \mathrm{mmol} / \mathrm{L}$ with a range of $0.7-9.5 \mathrm{mmol} / \mathrm{L}$. Twelve out of the 100 samples were $\geq 4.0 \mathrm{mmol} / \mathrm{L}$ at baseline.

Another 102 whole blood samples (52 venous, 50 arterial) were used to examine the stability of lactate concentration over time in slushed ice conditions $\left(0.1-0.2^{\circ} \mathrm{C}\right)$. The mean baseline values for the venous and arterial specimens were $3.0 \pm 2.0 \mathrm{mmol} / \mathrm{L}$ and $4.1 \pm 3.4 \mathrm{mmol} / \mathrm{L}$, respectively. When the arterial and venous samples were combined, the baseline values were $3.5 \pm 2.8 \mathrm{mmol} / \mathrm{L}$ with a range of $1.0-13.4 \mathrm{mmol} / \mathrm{L}$. Thirty-six out of the $102 \mathrm{sam}-$ ples were $>4.0 \mathrm{mmol} / \mathrm{L}$ at baseline. All samples were within the analytical measurement range of the analyzer for whole blood lactate $(0.7-16.0 \mathrm{mmol} / \mathrm{L})$.

The rate of increase in whole blood arterial lactate and whole blood venous lactate concentrations were similar and were therefore grouped together (Table 1). Whole blood lactate values increased under room temperature conditions but stayed relatively stable under slushed ice conditions (Figs. 1-3). Slushed ice kept blood lactate from increasing by a CAP-defined clinically important amount of 0.4 mmol/L (Table 1, Fig. 3). In fact, only 6 samples on ice (6\%) showed a change of $\geq 0.4 \mathrm{mmol} / \mathrm{L}$ after $\sim 85 \mathrm{~min}$ (Fig. 3). In contrast, $99 \%$ of all samples stored at room temperature showed a change of $\geq 0.4 \mathrm{mmol} / \mathrm{L}$ after $\sim 85 \mathrm{~min}$ (Fig. 2). 


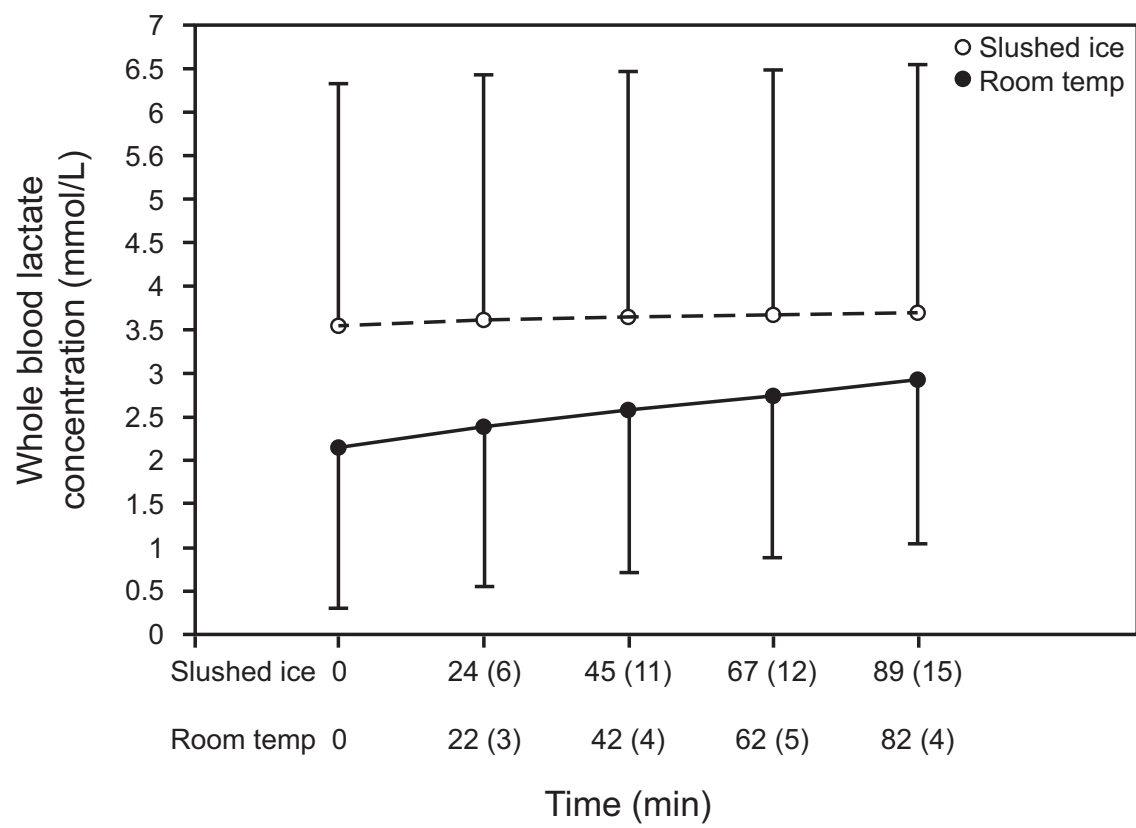

Fig. 1. Whole blood lactate samples stored at room temperature versus slushed ice. Room temperature increased blood lactate concentration by $0.008 \mathrm{mmol} / \mathrm{L} / \mathrm{min}$ for both arterial and venous samples. In contrast, placing the specimens on slushed ice prevented a clinically meaningful change in blood lactate concentration, even after $\sim 90 \mathrm{~min}$. Error bars represent standard deviation.

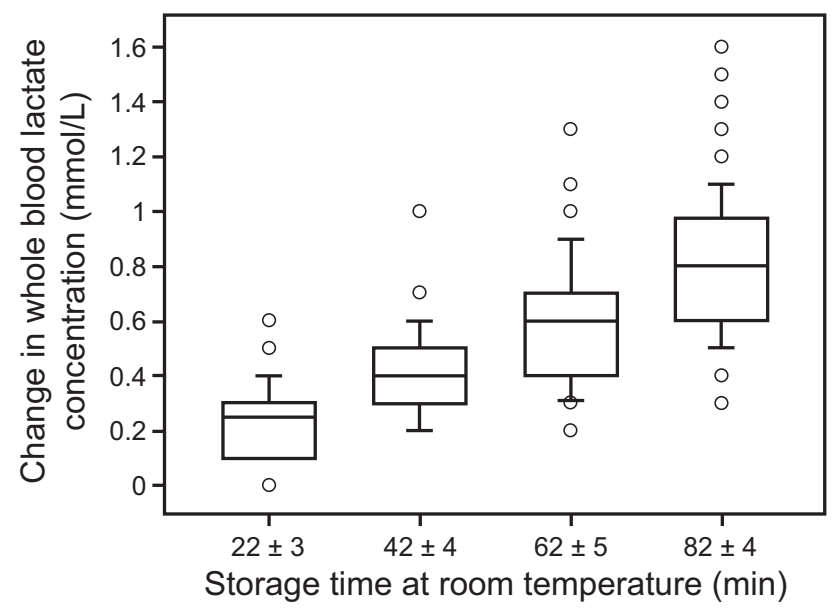

Fig. 2. The change in whole blood lactate concentration at room temperature $\left(22-24^{\circ} \mathrm{C}\right)$. In this box and whisker plot $(n=100)$, the 25th-75th percentile is represented by the central box. The middle line represents the median. The whiskers (error bars) above and below each box represents the data above the 90th percentile or below the 10th percentile, respectively. The circles represent data above the 90th percentile or below the 10th percentile, respectively. There is no lower error bar at $22 \pm 3$ min because the 10th and 25th percentile values were the same. There was a statistical significance in the mean change at each time (Bonferroni corrected, $P<.0001$ ).

Forward multiple regression results indicated an overall model of one predictor (time, in min) that significantly predicted the change in lactate concentration stored at room temperature [adjusted $\mathrm{r}^{2}=0.56, F(1,388)=497.4, P<$

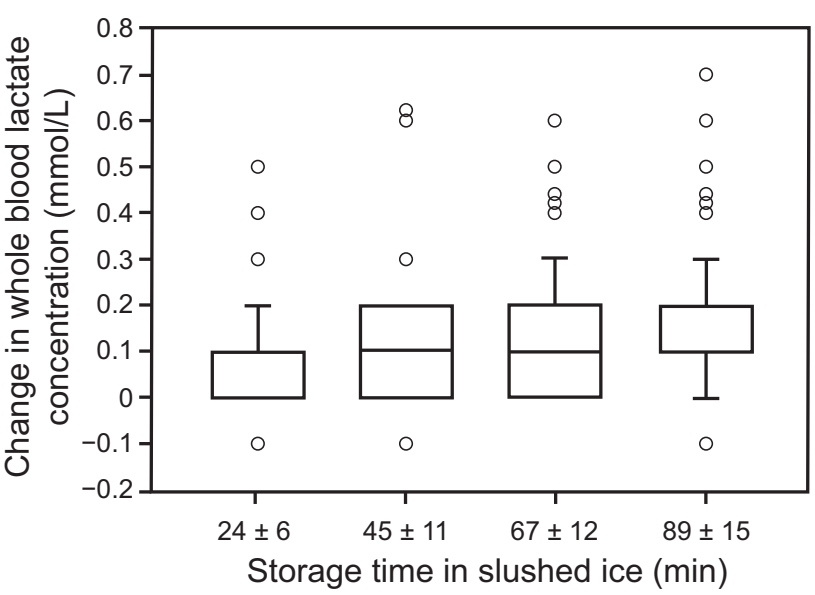

Fig. 3. The change in whole blood lactate concentration in slushed ice conditions $\left(0.1-0.2^{\circ} \mathrm{C}\right)$. In this box and whisker plot $(n=102)$, the 25th-75th percentile is represented by the central box. The middle line represents the median. The whiskers (error bars) above and below each box represents the data above the 90th percentile or below the 10th percentile, respectively. The circles represent data above the 90th percentile or below the 10th percentile, respectively. Where no errors bars are present, the 10th and 25th percentiles are the same, or the 75th and 90th percentiles are the same. Where no median line is present, there was no data (ie, there is no $0.05 \mathrm{mmol} / \mathrm{L}$ data point at $24 \pm 6 \mathrm{~min}$, and there is no $0.15 \mathrm{mmol} / \mathrm{L}$ data point at $89 \pm 15 \mathrm{~min}$ ). Only $2-6 \%$ of the specimens demonstrated a meaningful change in whole blood lactate concentration of $\geq 0.4 \mathrm{mmol} / \mathrm{L}$ at any timepoint.

.001]. The sample type (venous vs arterial) did not influence the model. Data screening led to the elimination of 11 cases for a total of 399 cases that remained in the model. 


\section{Stability of Whole Blood Lactate Specimens}

Approximately $56 \%$ of the variance in the change in whole blood lactate concentration was shared by the amount of time a sample remained at room temperature before analysis. Regression equation 1 is shown below:

Change in lactate $(\mathrm{mmol} / \mathrm{L})=0.008 \times($ time sample is stored at room temperature in $\mathrm{min})+0.069$ with adjusted $\mathrm{r}^{2}$ $=0.56, \mathrm{SEE}=0.166 \mathrm{mmol} / \mathrm{L}, F(1,388)=497.4, P<$ .001 , Durbin-Watson $=2.03$, variance inflation factor $=$ 1.0 , with a $95 \% \mathrm{CI}$ for the slope of $0.008-0.009 \mathrm{mmol} / \mathrm{L} /$ min.

In terms of the prediction accuracy of the linear model for regression equation 1, the correlation coefficient between the predicted change in lactate concentration associated with the actual change in lactate concentration was 0.74 (95\% bootstrapped CI $=0.65-0.84, P<.001$, $n=71$ cases), validating the accuracy of the model. In this instance, a sample sitting at room temperature for 41 min would show an increase in blood lactate concentration of $0.4 \mathrm{mmol} / \mathrm{L}$ compared to baseline.

Reversing the independent and dependent variables, forward multiple regression results indicated an overall model of one predictor (change in lactate concentration, in $\mathrm{mmol} / \mathrm{L}$ ) that significantly predicted the amount of time a sample was stored at room temperature before analysis [adjusted $\mathrm{r}^{2}=0.57, F(1,383)=499.3, P<.001$ ]. The sample type (venous vs arterial) did not influence the model. Data screening led to the elimination of 15 cases. About $56 \%$ of the variance in the amount of time a sample was stored at room temperature before analysis was shared by the change in whole blood lactate concentration. Regression equation 2 is shown below:

Time sample is stored at room temperature $(\mathrm{min})=$ $68.62 \times$ (change in lactate concentration, $\mathrm{mmol} / \mathrm{L})+17.30$ with adjusted $\mathrm{r}^{2}=0.56$, SEE $=15.0 \mathrm{~min}, F(1,383)=$ 493.5, Durbin-Watson $=1.2$, variance inflation factor $=1$, $P<.001$, with a $95 \%$ CI for the slope of 62.5-74.7 min.

In terms of the prediction accuracy of the linear model, the correlation coefficient between the estimated versus actual time that a sample is stored, for a given change in lactate concentration, was $0.83(95 \%$ bootstrapped CI $=$ $0.75-0.89, P<.001$, no. $=77$ cases $)$, validating the accuracy of the model.

As such, to elicit an increase in whole blood lactate concentration of $0.4 \mathrm{mmol} / \mathrm{L}$ (compared to baseline), the sample would have to sit at room temperature for $\sim 45 \mathrm{~min}$. Only $5 \%$ of all samples that would change by at least 0.4 $\mathrm{mmol} / \mathrm{L}$ would do so after $\leq 20 \mathrm{~min}$ at room temperature.

When multiple linear regressions were performed using samples stored on ice, the full models accounted for $<25 \%$ of the total variance, so they were not included. In fact, only $\sim 5 \%$ of the variance in the change in whole blood lactate concentration was shared by the amount of time a sample was stored in slushed ice before analysis. This is because slushed ice prevented a clinically meaningful increase in whole blood lactate concentration over the $\sim 90$-min period, such that the slope remained nearly zero.

\section{Discussion}

The purpose of the study was to demonstrate the effects of time and ice on whole blood lactate values and to determine how much time whole blood lactate specimens should be kept at room temperature before a CAP-defined increase of $\geq 0.4 \mathrm{mmol} / \mathrm{L}$ would occur. Based on the data of 100 samples and measurements over 5 different times of up to $109 \mathrm{~min}$, we determined that $\mathrm{a} \geq 0.4 \mathrm{mmol} / \mathrm{L}$ increase in whole blood lactate would not occur until $45 \mathrm{~min}$ at room temperature (Regression equation 2). This means that, on average, lactate increases at a rate of $0.008 \mathrm{mmol} / \mathrm{L} / \mathrm{min}$ at room temperature. The large sample size makes this study generalizable to a broad audience and provides the largest dataset to date.

Typical laboratory protocols for processing whole blood lactate specimens vary greatly. After performing a cursory search for clinical lab policies online, the acceptable drawto-analysis time varies widely from $10 \mathrm{~min}$ to $120 \mathrm{~min}$ among various institutions. There may be a benefit to using data-driven protocols to standardize practices as more studies like this are published.

Our results indicate that whole blood lactate remained stable at room temperature for $\sim 45 \mathrm{~min}$, and for up to 90 $\mathrm{min}$ in slushed ice. Although samples are usually processed quickly in clinical practice, situations occur where delayed processing for that length of time can occur. For example, travel delays to the lab (eg, tube systems being down), processing delays where lactate is not prioritized, or situations where lactate specimens are mixed with a multitude of other lab specimens if there is no dedicated blood gas lab in the hospital (ie, lactate specimens compete with all the other specimens received within a core lab). Also, in some hospitals, there may be an insufficient number of analyzers to process the specimens quickly.

Previous studies examining the stability of whole blood lactate at room temperature have had important limitations to study design and sample size (Table 2) ${ }^{5-12}$ Some studies had limited sample sizes of 3-11 subjects, ${ }^{5-7,9,11}$ which is too few for a meaningful clinical decision. In fact, the Clinical and Laboratory Standards Institute has made their recommendation of storage time of whole blood lactate at room temperature to be no longer than $15 \mathrm{~min},{ }^{13}$ based on data from studies that used only $3-5$ subjects. ${ }^{79}$ Supporting studies have been limited by small sample sizes and lack of a recommendation as to what a clinically meaningful change in blood lactate should be. We assert that a meaningful increase in whole blood lactate is $\geq 0.4 \mathrm{mmol} / \mathrm{L}$, which is the value the College of American Pathologists use in their surveys when they compare lactate values between the same 
Stability of Whole Blood Lactate Specimens

Table 2. Studies Describing Changes in Whole Blood Lactate Concentration at Room Temperature

\begin{tabular}{|c|c|c|c|c|}
\hline Study & Sample Size & Sample & Rate of Change, $\mathrm{mmol} / \mathrm{L} / \mathrm{min}$ & Major Issues \\
\hline Present study & 100 & Heparinized whole blood & $0.008(0.008-0.009)$ & None \\
\hline Seymour et $\mathrm{al}^{5}$ & 5 & Heparinized whole blood & $0.012(0.008-0.016)$ & $\begin{array}{l}\text { Limited amount of subjects } \\
\text { Range of values too low }(0.9-2.2 \mathrm{mmol} / \mathrm{L}) \\
\text { Measured period too short }(30 \mathrm{~min}) \\
\text { No linear regression equation provided }\end{array}$ \\
\hline Hedberg et $\mathrm{al}^{6}$ & 5 & Heparinized whole blood & 0.009 & $\begin{array}{l}\text { Limited amount of subjects } \\
\text { No linear regression equation } \\
\text { No SD or } 95 \% \text { CI provided }\end{array}$ \\
\hline Calatayud and Tenias ${ }^{3}$ & 59 & Heparinized whole blood & $0.012(0.010-0.013)$ & No linear regression equation provided \\
\hline Kost et $\mathrm{al}^{7}$ & 3 & Heparinized whole blood & 0.01 & $\begin{array}{l}\text { Limited amount of subjects } \\
\text { Measured period too short }(45 \mathrm{~min}) \\
\text { No linear regression equation provided }\end{array}$ \\
\hline Noordally and Vincent ${ }^{8}$ & 17 & Heparinized whole blood & 0.02 & $\begin{array}{l}\text { Limited amount of subjects } \\
\text { Measured period too short }(8 \mathrm{~min}) \\
\text { No linear regression equation provided } \\
\text { No SD or } 95 \% \text { CI provided }\end{array}$ \\
\hline Toffaletti et $\mathrm{al}^{9}$ & 5 & Heparinized whole blood & 0.017 & $\begin{array}{l}\text { Limited amount of subjects } \\
\text { Measured period too short }(30 \mathrm{~min}) \\
\text { No linear regression equation provided } \\
\text { No SD or } 95 \% \text { CI provided }\end{array}$ \\
\hline Wandrup et $\mathrm{al}^{10}$ & ND & Heparinized whole blood & 0.007 & $\begin{array}{l}\text { Number of patient samples not provided } \\
\text { No SD or } 95 \% \text { CI provided }\end{array}$ \\
\hline Geyssant et al ${ }^{11}$ & 11 & Heparinized whole blood? & $0.008(0.007-0.015)$ & $\begin{array}{l}\text { Limited amount of subjects } \\
\text { Range of values too low }(1.1-6.8 \mathrm{mmol} / \mathrm{L})\end{array}$ \\
\hline
\end{tabular}

$\mathrm{ND}=$ no data

peer group (instrument) from different laboratories across the United States.

Another limitation to studies that have examined the stability of whole blood lactate at room temperature is the length of time that a specimen was stored at room temperature. For example, some studies have analyzed the change in whole blood lactate over $8 \mathrm{~min},{ }^{8} 30 \mathrm{~min},{ }^{5,9}$ or $45 \mathrm{~min},{ }^{7}$ which is not a sufficient time period to calculate the rate of change.

A further limitation of the studies that have examined the stability of whole blood lactate at room temperature is that no linear regression equation was presented in their articles, including adjusted $\mathrm{R}^{2}$, standard error of the estimate, and other parameters to validate the rate of change in whole blood lactate over time. ${ }^{5-9,12}$ As such, there is no indication as to the prediction accuracy of their slopes. Our study provides meaningful regression equations that were tested for prediction accuracy and are now useful for clinical practice.

Our data imply that storing a whole blood lactate specimen on ice will not result in an increase of $\geq 0.4 \mathrm{mmol} / \mathrm{L}$ if the draw-to-analysis time is $<45 \mathrm{~min}$. In 2019 , the mean \pm SD draw to report time for all 32,284 whole blood lactate specimens received at our lab was $10.9 \pm 5.1 \mathrm{~min}$, and only $\sim 6 \%$ and $\sim 1 \%$ of specimens had a draw-to-report time of $\geq 20$ and $\geq 30 \mathrm{~min}$, respectively (Fig. 4), similar to the draw-to-report times of blood gases $\left(\mathrm{pH}, \mathrm{P}_{\mathrm{O}_{2}}, \mathrm{P}_{\mathrm{CO}_{2}}\right)$. These data suggest that omitting the use of ice would not have resulted in a significant difference in reported values. By omitting ice as a mandatory requirement during storage and transport, several positive outcomes may be possible: less water waste, less syringe waste, less blood waste, and less staff time. These are all positive aspects of a more sustainable environment. There may also be less infection risk to the patient as the arterial or intravenous lines are accessed less frequently.

This study has several important strengths. First, this study boasts the largest sample size to date. Second, it includes a wide range of whole blood lactate values from various patients. Third, this study uses rigorous statistical analyses. Fourth, we provide regression equations for clinical practice which have been verified for prediction accuracy. We also recognize several limitations. Although our sample size is the largest to date, additional samples may marginally tighten our statistical confidence and allow for assessment of additional values at extreme ranges. Additionally, because patient data were not extracted, it is not possible to address to what extent certain medical conditions or metabolic processes are represented in this data set. Indeed, this is a single-center study, and it would be more convincing to have these results duplicated at other institutions. It is also difficult to truly define what a 


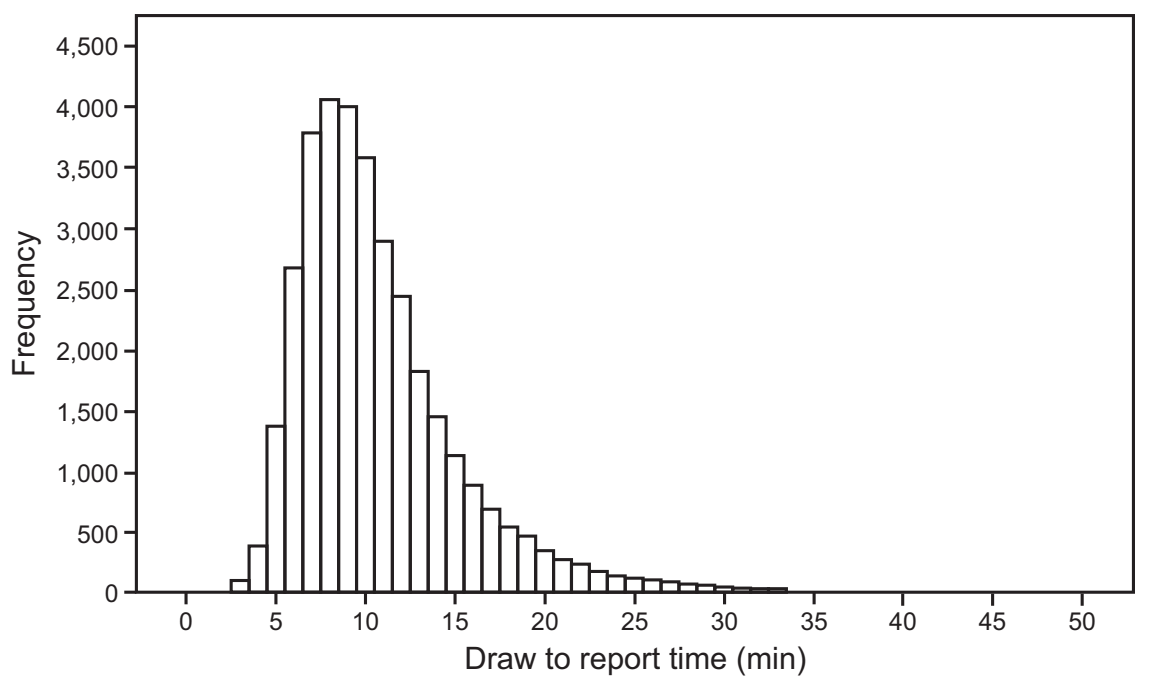

Fig. 4. Histogram demonstrating the frequencies of the draw to report time for each whole blood lactate specimen received at our lab in 2019. The mean \pm SD draw to report time was $10.9 \pm 5.1 \mathrm{~min} ; \sim 6 \%$ of specimens had a draw-to-report time of $\geq 20 \mathrm{~min}$, and $\sim 1 \%$ of the specimens had a draw-to-report time of $\geq 30 \mathrm{~min}$.

clinically meaningful difference is, though our cut-off of $\geq$ $0.4 \mathrm{mmol} / \mathrm{L}$ has a strong rationale based on CAP definitions.

\section{Conclusions}

In the largest analysis of whole blood lactate specimens to date, our results indicate that whole blood lactate increases by $0.008 \mathrm{mmol} / \mathrm{L} / \mathrm{min}$ at room temperature; when stored at slushed ice conditions, whole blood lactate increases by $0.001 \mathrm{mmol} / \mathrm{L} / \mathrm{min}$. When the draw-to-analysis time is $<45 \mathrm{~min}$, storing whole blood lactate samples at room temperature did not result in a clinically meaningful difference of $\geq 0.4 \mathrm{mmol} / \mathrm{L}$. Furthermore, the rate of change in whole blood lactate at room temperature is independent of the sample type (arterial or venous). Further work is needed to validate our important practice-changing findings.

\section{ACKNOWLEDGMENTS}

The authors thank the staff of the blood gas lab at University of California Davis Medical Center for helping with some aspects of data collection throughout their busy shifts.

\section{REFERENCES}

1. Andersen LW, Mackenhauer J, Roberts JC, Berg KM, Cocchi MN, Donnino MW. Etiology and therapeutic approach to elevated lactate levels. Mayo Clin Proc 2013;88(10):1127-1140.

2. Shapiro NI, Howell MD, Talmor D, Nathanson LA, Lisbon A, Wolfe $\mathrm{RE}$, et al. Serum lactate as a predictor of mortality in emergency department patients with infection. Ann Emerg Med 2005;45(5):524528.
3. Callaway DW, Shapiro NI, Donnino MW, Baker C, Rosen CL. Serum lactate and base deficit as predictors of mortality in normotensive elderly blunt trauma patients. J Trauma 2009;66(4):1040-1044.

4. Rose IA, Warms JV. Control of glycolysis in the human red blood cell. J Biol Chem 1966;241(21):4848-4854.

5. Seymour CW, Carlbom D, Cooke CR, Watkins TR, Bulger EM, Rea TD, Baird GS. Temperature and time stability of whole blood lactate: implications for feasibility of pre-hospital measurement. BMC Res Notes 2011;4(1):169.

6. Hedberg P, Majava A, Kiviluoma K, Ohtonen P. Potential preanalytical errors in whole-blood analysis: effect of syringe sample volume on blood gas, electrolyte and lactate values. Scand J Clin Lab Invest 2009;69(5):585-591.

7. Kost GJ, Nguyen TH, Tang Z. Whole-blood glucose and lactate. Trilayer biosensors, drug interference, metabolism, and practice guidelines. Arch Pathol Lab Med 2000;124(8):1128-1134.

8. Noordally O, Vincent JL. Evaluation of a new, rapid lactate analyzer in critical care. Intensive Care Med 1999;25(5):508-513.

9. Toffaletti J, Hammes ME, Gray R, Lineberry B, Abrams B. Lactate measured in diluted and undiluted whole blood and plasma: comparison of methods and effect of hematocrit. Clin Chem 1992;38(12): 2430-2434.

10. Wandrup J, Tvede K, Grinsted J, Jordening H. "Stat” measurements of L-lactate in whole blood and cerebrospinal fluid assessed. Clin Chem 1989;35(8):1740-1743.

11. Geyssant A, Dormois D, Barthelemy JC, Lacour JR. Lactate determination with the lactate analyser LA 640: a critical study. Scand J Clin Lab Invest 1985;45(2):145-149.

12. Calatayud O, Tenías JM. Effects of time, temperature and blood cell counts on levels of lactate in heparinized whole blood gas samples. Scand J Clin Lab Invest 2003;63(4):311-314.

13. Clinical and laboratory Standards Institute (CLSI). Blood gas and $\mathrm{pH}$ analysis and related measurements: approved guidelines-second edition. CLSI document C46-A2 (ISBN 1-56238-694-8). Clinical and Laboratory Standards Institute, 950 West Valley Road, Suite 2500, Wayne, Pennsylvania 19087 USA, 2009. 